\title{
Análisis del concepto de equivalencia en la traducción institucional del ámbito de la Unión Europea
}

\author{
José María Castellano Martínez \\ Institut Supérieur de Traducteurs et Interprètes (Haute École de \\ Bruxelles) \\ 152camaj@uco.es \\ https://dx.doi.org/10.12795/futhark.2012.i07.02
}

\begin{abstract}
This paper aims to analyze the concept of equivalence which is registered within the specialized context of the European Union institutions. Firstly, a historical sketch of the principal theories about equivalence is provided in order to studying the said concept from three different perspectives, namely, linguistics -the study of this concept in relation to multilingualism policy-, legal -the relevance of the legal and institutional framework according to this concept of equivalence-, and finally, a perspective from the translation studies to investigate the notions of ST and TT as well as the act of linguistic translation it-self; between other aspects related to translating in this specialized field. Finally, this work aims to provide a proposed definition for the said concept of equivalence by considering the conclusions from the previous issues, considered as limits defining this context of specialization.
\end{abstract}

Keywords: Equivalence, Institutional Translation, European Union, Multilingualism, Translation Skills.

Resumen: En el presente trabajo se procede a analizar el concepto de equivalencia que se inscribe en el contexto especializado de las instituciones de la Unión Europea. En primer lugar, se ofrece un esbozo histórico de las principales corrientes teóricas que han surgido sobre la equivalencia de tal modo que, a continuación, se analice dicho concepto a partir de tres perspectivas diferentes, a saber, lingüística, en la que se estudiará este concepto en relación con la política del Multilingüismo; jurídica, es decir, la relevancia que el marco legal e institucional donde se da la relación equivalente tiene al respecto; $y$, finalmente, desde la perspectiva de la traductología, para investigar las nociones de TO y TM así como el propio acto de traslación lingüística, entre otros aspectos, en dicho ámbito especializado. Por último, se pretende ofrecer una propuesta de definición para este concepto considerando las conclusiones extraídas de las cuestiones anteriores en tanto que límites definitorios de dicho contexto de especialización.

Palabras clave: Equivalencia, Traducción Institucional, Unión Europea, Multilingüismo, Competencias Traductoras 


\section{Introducción}

Todo acto de traducción o interpretación pretende alcanzar de forma directa o indirecta un valor equivalente en el nuevo texto respecto del original. Así pues, la equivalencia resulta inherente a cualquier proceso de translación lingüística que se precie, ya sea en un nivel escrito $u$ oral. No obstante, este concepto resulta polémico y ha planteado discrepancias que quedan reflejadas en la amplia variedad de enfoques teóricos que a lo largo de las últimas décadas han surgido sobre esta cuestión. En términos generales, el concepto de equivalencia se concibe como un fenómeno semántico, aunque también pragmático, ya que son varios los factores extralingüísticos que intervienen en su conceptualización -de ahí que se den diferentes teorías- por lo que podría añadirse también que se trata de una noción subjetiva, siendo, por ende, máximo exponente de la esencia de cualquier traducción.

En el ámbito de la traducción de documentos provenientes de las instituciones de la Unión Europea, el concepto de equivalencia, como no podría ser de otra manera, resulta fundamental tanto a nivel semántico, o dicho de otro modo, lingüístico; como a nivel pragmático, en este caso, político y jurídico. De hecho, podría afirmarse que se trata de un valor intrínseco a cualquier instrumento comunitario, en virtud tanto de la política lingüística -presente desde un principio en las actividades de las instituciones comunitarias- como del marco jurídico en el que se autentifican por iguales y equivalentes todas las versiones lingüísticas. Al mismo tiempo, cabe destacar la particularidad del contexto institucional en el que el concepto de equivalencia se inscribe. Se trata, pues, de un ámbito especializado que condiciona a la propia noción de «equivalente» y le aporta un sentido único que fuera de él carecería de sentido.

Se puede considerar, pues, que la Unión Europea presenta un entorno ideal en el que el valor de la equivalencia -que viene previamente condicionado por diversos factores extralingüísticos analizados a continuación- adquiere, más que nunca, un significado absoluto como punto de partida y de llegada en cualquier documento traducido, sea cual sea la combinatoria lingüística implicada, la tipología textual o la temática sobre la que verse. Por ello, la labor traductora que se lleva a cabo en el seno de los servicios lingüísticos de la Unión Europea -en los que también se deben incluir la Interpretación y la Terminología-, ofrece un campo de estudio

Futhark 7 (2012) Castellano, Análisis del concepto, 43-84

ISSN 1886-9300 
apropiado para constatar si las principales corrientes teóricas que existen hasta hoy sobre la equivalencia pueden ser aplicables a este tipo de traducción o si, de lo contrario, se debería prestar una atención especial al concepto de equivalencia en este marco institucional. Concretamente, en lo que se refiere a la traducción, entendida no sólo como proceso de transmisión de significados y conceptos de una realidad lingüística a otra, sino también como objeto final de dicho proceso, es decir, como nuevo texto.

\section{Evolución, teorías y clasificación del concepto de equivalencia en traducción}

Para abordar el trabajo sobre la equivalencia en el campo de estudio aquí propuesto, resulta indispensable analizar y contrastar las diversas teorías que en el último siglo han surgido respecto a este concepto. En primer lugar, será conveniente hablar de las propuestas de R. Jakobson, E. Nida y J. Catford así como de las críticas que éstas han recibido por parte de otros autores.

En 1959, R. Jackobson ${ }^{1}$ publica un ensayo en lengua inglesa titulado On linguistic Aspects of Translation en el que trata desde una perspectiva lingüística el concepto de equivalencia. En este trabajo, el autor afirma que la equivalencia, en el sentido literal del término, no existe; se debería hablar en todo caso de «equivalencia parcial», ya que no se traducen unidades lingüísticas sino ideas, conceptos o mensajes. En lo que respecta a la traducción de un texto de una LO a una LM, Jackobson considera que aquello que se traduce es el mensaje del texto a una nueva lengua, por lo que cualquier mensaje se podría traducir a cualquier idioma, pues cada uno de ellos posee los mecanismos pertinentes para representarlo.

Unos años más tarde, E. Nida irrumpe con su obra Toward a Science of Translating with Special Reference to Principles and Procedures involved in Bible Translation, la cual supone un antes y un después no sólo para los estudios sobre equivalencia, sino para la propia Traductología. Si el autor anterior propuso un enfoque lingüístico para abordar esta cuestión, Nida establece un enfoque comunicativo a partir del cual definirá al proceso traductor como un acto que consiste en reproducir en el TM una equivalencia que sea

\footnotetext{
1 Jackobson, Roman, On linguistic Aspects of Translation, Nueva York, R.A. Broker, 1966.

Futhark 7 (2012)

Castellano, Análisis del concepto, 43-84
}

ISSN 1886-9300 
lo más fiel posible al TO y que se caracteriza por respetar, en primer lugar, el contenido y, en segundo, el estilo 2 .

Según esta afirmación, se distinguen dos tipos de equivalencia, a saber, equivalencia formal -aquella que es fruto de una traducción más literal en la que prima mantener con escrúpulo la forma del original- y equivalencia dinámica -aquella en la que importa más comunicar la idea expresada en el TO de acuerdo con las particularidades de la lengua del TM. Este último concepto ha recibido más tarde la denominación de equivalencia funcional o equivalencia del efecto, además de ser objeto de estudio para otros autores como P. Newmark ${ }^{3}$ o, posteriormente, Y. Higashino ${ }^{4}$, quienes consideran que una posible estrategia de traducción en ese sentido dinámico o funcional podría ser el recurso de la «equivalencia cultural», es decir, sustituir un elemento cultural del TO por otro que consiga un efecto equivalente en el TM, en armonía con la lengua y cultura de llegada. En este sentido, resulta de gran interés destacar igualmente las consideraciones realizadas por B. Hatim e I. Mason ${ }^{5}$ sobre el concepto de equivalencia dinámica y su relación con la equivalencia cultural:

El traductor no puede aspirar a producir siempre en sus lectores la misma impresión que siente un lector nativo ante la obra escrita en su propia lengua. Esta meta es en muchos casos inasequible. ¿Cómo podría el lector de la traducción española de una novela japonesa fuertemente costumbrista sentir la misma impresión que los lectores nativos ante la obra original? Aunque la traducción saliera tan fluida que pudiera leerse, desde el punto de vista puramente lingüístico, con igual naturalidad que el original, su contenido produciría en los lectores españoles una impresión de exotismo, que, por otra parte, sin duda constituiría una gran riqueza".

Este cruce de visiones son clara muestra de la subjetividad que el concepto de equivalencia plantea, incluso para determinadas

\footnotetext{
${ }^{2}$ NIDA, Eugene, Toward a Science of Translating with Special Reference to Principles and Procedures involved in Bible Translation, Leiden y Boston, Brill, 1964: 4.

NeWMARK, Peter, A Textbook of Translation, Hertfordshire, Prentice Hall International, 1988: 82-83.

${ }^{4}$ HIGASHINO, Yumi, "Cultural equivalence: its effectiveness and complications. Has "white gloves» achieved the equivalent effect of "shiro tabi»?", en Interpretation Studies (JAIS, the Japan Association for Interpretation Studies), núm. 1, 2001: 55.

${ }^{5}$ HATIM, Basil; MASON, Ian, Teoría de la traducción. Una aproximación al discurso, Barcelona, Ariel, 1995: 392.
}

Futhark 7 (2012)

Castellano, Análisis del concepto, 43-84

ISSN $1886-9300$ 
autoridades de la Lingüística y la Traductología. Así, mientras que Nida, y por consiguiente, Newmark o Higashino contemplan la equivalencia dinámica-funcional como solución para conseguir un efecto determinado en el público receptor del TM que sea equivalente al del original, Hatim y Mason estiman que, pese a la indiscutible riqueza que este efecto de equivalencia pueda aportar a la traducción, jamás ocasionará el mismo efecto del original en el público receptor del nuevo texto.

Por su parte, J. C. Catford ${ }^{6}$ aporta un nuevo matiz al enfoque comunicativo de Nida en su obra $A$ Linguistic Theory of Translation. An Essay in Applied Linguistics. Para el autor, poco importa que el significado de un determinado fragmento del TO coincida con el significado de otro fragmento en el TM; según su criterio, la equivalencia entre un fragmento y otro existirá cuando el traducido realice la misma función comunicativa que el original, sin tener en cuenta que el significado se corresponda. Se trata, entonces, de una equivalencia a nivel textual, donde el contexto de la situación comunicativa de cada una de las lenguas implicadas condicionará la traducción.

A esta definición se suman también $S$. Peña y $M$. J. Fernández Guerrero ${ }^{7}$, quienes consideran que el concepto de equivalencia se equipara a un fenómeno textual, ya que sólo pueden ser equivalentes de una lengua a otra los valores comunicativos de ambos textos. Asimismo, E. Sánchez Trigo ${ }^{8}$, en su Teoría de la traducción. Convergencias y divergencias, coincide con el concepto de equivalencia propuesto por Catford, aunque matiza que esta definición -fundamentada en unidades muy concretas, como los fragmentos- no es adecuada para el propio sentido de equivalencia textual, que debería contemplarse desde una perspectiva más abarcadora.

Frente a estas posturas, que por lo general atribuyen al concepto de equivalencia un valor unívoco en cuanto a la aplicabilidad del mismo, resulta pertinente hacer referencia a otros enfoques en los que se recogen varios tipos de equivalencia. En

\footnotetext{
${ }^{6}$ CATford, John C., A Linguistic Theory of Translation: an Essay on Applied Linguistics, Londres, Oxford University Press (OUP), 1965.

7 PENAA, Salvador; HERNÁNDEZ GUERRERO, María Jose, Traductología, Málaga: Universidad de Málaga, 1994.

${ }^{8}$ SÁNCHEZ TRIGO, Elena, Teoría de la traducción. Convergencias y divergencias, Vigo, Servicio de Publicaciones de la Universidad de Vigo, 2002.

Futhark 7 (2012)

Castellano, Análisis del concepto, 43-84
}

ISSN 1886-9300 
principio, es pertinente considerar lo expuesto por A. Popovič en su Dictionary for the Analysis of Literary Translation, en la que establece una clasificación de cuatro tipos de equivalencia atendiendo a la modalidad traductora que se aplique, así, se distingue entre equivalencia lingüística -traducción de una unidad léxica por otra unidad léxica-, equivalencia paradigmática -donde prima la traslación de las unidades gramaticales-, equivalencia estilística -que pretende reflejar en el TM tanto el significado como la expresividad del TO- y equivalencia textual -con una definición similar a la anteriormente vista-. Al lingüista y traductor eslovaco, le sigue W. Koller ${ }^{10}$, quien llega a diferenciar hasta cinco marcos de equivalencia en virtud de la relación que exista en los TO y TM y las LO y LM implicadas en una traducción.

El motivo de esta «relación» no viene determinada a priori por el concepto de equivalencia, sino que será a posteriori, una vez la traducción esté terminada, cuando de manera adicional y de acuerdo con el resultado final se pueda establecer un marco u otro de equivalencia. Por ello, si prevalece una situación extralingüística en el TM se tratará de una equivalencia denotativa (denotative Äquivalenz), en el caso de prestar mayor atención a las connotaciones implicadas se hablará de una equivalencia connotativa (konnotative Äquivalenz); si en la traducción impera la norma o las características propias de un lenguaje concreto, ésta se enmarcará en una equivalencia texto-normativa (textnormative Äquivalenz) y en el caso de dar más importancia al efecto de equivalencia en el receptor del TM, una equivalencia pragmática (pragmatische Äquivalenz). Por último, si la traducción atiende a cuestiones estilísticas o retóricas, W. Koller propone un marco de equivalencia formal-estilística (formal-ästhetische Äquivalenz), característica en los textos poéticos, entre otros ${ }^{11}$.

\footnotetext{
9 Popovič, Anton, Dictionary for the Analysis of Literary Translation, Edmonton, Department of Comparative Literature - University of Alberta, 1976.

${ }^{10}$ KOLLER, Werner, Einführung in die Übersetzungswissenschaft, Heidelberg, Quelle \& Meyer, 1979 y KOLLER, Werner, "Der Begriff der Äquivalenz in der Übersetzungswissenschaft", en FABRICIUS-HANSEN, C.; OsTBO, J. (eds.), Übertragung Annährung, Angleichung. Sieben Beiträge zu Theorie und Praxis des Übersetzens, Fráncfort del Meno, Peter Lang, 2000: 24.

${ }^{11}$ Por otra parte, W. KOLLER (2000: 11) plantea también la posibilidad de distinguir entre dos tipos de concepto de equivalencia. En primer lugar, el concepto teóricodescriptivo (theoretisch-descriptiver Begriff), donde la relación entre un texto y otro se fundamenta en la traducción como proceso; y, por otra parte, el concepto normativoFuthark 7 (2012) Castellano, Análisis del concepto, 43-84
}

ISSN 1886-9300 
Por su parte, S. Bassnett ${ }^{12}$ propone un análisis de equivalencia estructurado en tres niveles diferentes que se fundamentan en la sintaxis -cuando la equivalencia se da entre unidades lingüísticas-, la semántica -si la relación de equivalencia se efectúa entre unidades lingüísticas y el significado de las mismas- y la pragmática -en la que se incluye a los individuos que utilizan las anteriores además del contexto donde se desarrolla esta relación de equivalencia-.

En otro orden de cosas, son escasos los estudios realizados sobre el concepto de equivalencia en el ámbito institucional de la Unión Europea. No obstante, no se han de obviar las interesantes aportaciones realizadas por autores y profesionales que trabajan en los servicios lingüísticos de los órganos comunitarios. Así, S. Sarcevic considera que «the principle of fidelity to the source text is losing ground to the principle of fidelity to the single instrument ${ }^{13}$. Dicho de otro modo: el propio contexto comunitario devalúa la presencia del TO a favor del instrumento que éste representa, es decir, al ser todas las versiones lingüísticas equivalentes, la noción de TO desaparece, pues lo que importa es la existencia de ese mismo instrumento en cada una de las lenguas oficiales. Aunque existen otras valoraciones en el ámbito traductológico de la Unión Europea, por ejemplo, el concepto de equivalencia existencial que plantea K. Koskinen ${ }^{14}$. Según esta finlandesa, la traducción a nivel comunitario no se contempla como un acto de comunicación, sino más bien como acto simbólico que refleja el principio del

crítico de la traducción (normativ-übersetzungskritischer Begriff) en el que se concede el mismo valor equivalente tanto al TO como al TM, por lo que se contempla la traducción como producto. Sin embargo, sobre esta propuesta, S. Bolaños (2002: 74) discrepa ya que según su criterio no existen dos conceptos, sino dos vías de diferente aplicación para un mismo concepto: «We do not agree fully with the above distinction of equivalence into two different concepts (...). Then our assumption is that as the concept of equivalence is dynamic, it can be used for analyzing both the process and the product of translation. Nonetheless, this should not mean that two concepts are being used: we would say instead that the same concept is being employed for two different purposes".

${ }_{12}$ BASSNET, Susan, Translation Studies, Londres y Nueva York, Routledge, 1980.

13 ŠARCEVIC, Susan, New Approach to Legal Translation, La Haya, Kluwer Law International, 1997: 112.

${ }^{14}$ KOSKINEN, Kaisa, "Institutional Illusions. Translating in the EU Commision", en The Translator, vol. 6, núm. 1, Manchester y Kinderhook (Nueva York), St. Jerome Publishing, 2000: 51

Futhark 7 (2012)

Castellano, Análisis del concepto, 43-84

ISSN 1886-9300 
multilingüismo. Además, Koskinen ${ }^{15}$ también adjetiva de «acultural» a este tipo de comunicación que se da en las instituciones europeas, ya que no se localiza a priori un TO y se pretende además redactar en todas las lenguas oficiales los mismos documentos en pro de la igualdad, pero, según la autora, en detrimento de las especificidades culturales de cada lengua y sociedad. Koskinen ${ }^{16}$ coincide también con Šarcevic al asegurar que la relación textual más importante en la traducción institucional de la Unión Europea no es el TO, ni tampoco el TM, sino los textos individuales vistos desde el contexto institucional, esto es, vistos como simples instrumentos. Por otra parte, T. J. M. van Els ${ }^{17}$ aborda la cuestión «cultural» anterior y admite que la simplificación del contenido y la sintaxis de los textos instituciones comunitarios implica una "desculturalización», que se aproxima, aunque con matices muchos más negativos, a las consideraciones anteriores de Koskinen.

Por último, cabe destacar las aportaciones de A. L. Kjaer ${ }^{18}$, quien afirma que en la Unión Europea, de hecho, no existe traducción como tal, sino más bien una reproducción textual interlingüística, ya que la finalidad principal del denominado acto traductor a nivel comunitario pretende, ante todo, recrear en todas las lenguas oficiales un texto simétrico que asegure la cohesión del mismo en todos los idiomas sin prestar atención a las particularidades y características de cada una de ellas.

\section{El concepto de equivalencia en el ámbito institucional europeo: análisis de perspectivas}

Antes de proponer una definición para el concepto de equivalencia en el ámbito especializado que supone el entramado

\footnotetext{
${ }^{15}$ KOSKINEN, Kaisa, "Institutional Illusions. Translating in the EU Commision", en The Translator, vol. 6, núm. 1, Manchester y Kinderhook (Nueva York), St. Jerome Publishing, 2000: 54

${ }^{16}$ KOSKINEN, Kaisa, "From Text to Context", en HELIN, Irmeli (ed.), Essays in Translation, Pragmatics and Semiotics, Helsinki: Multilingual Communication programme (MonAKO), 2002: 114.

${ }^{17}$ VAN ELS, Theo. J. M, "The European Union, its Institutions and its Languages: Some Language Political Observations", en Current Issues in Language Planning, vol. 2, núm. 4, Londres, pp. 311-360, 2001: 329-330.

${ }^{18}$ KJAER, Anne. L, "Legal Translation in the European Union. A Research Field in Need of a New Approach", en KREDENS, K.; GoźDŻ-ROSZKOWSKI S. (eds.), Language and the Law: International Outlooks, Fráncfort del Meno, Peter Lang, 2007: 69-95.

Futhark 7 (2012)

Castellano, Análisis del concepto, 43-84

ISSN $1886-9300$
} 
inter e intrainstitucional de la Unión Europea, resulta conveniente estudiar los diferentes factores que delimitan, configuran y motivan, a nuestro juicio, el concepto de equivalencia y, por ende, las labores de traducción, interpretación y terminología de las instituciones comunitarias. A continuación, se exponen dichos aspectos desde tres diferentes perspectivas, a saber, la lingüística, pues son lenguas las que se traducen e interpretan; la jurídica, es decir, el marco legal en el que se desarrolla la actividad institucional en todas las lenguas oficiales; y finalmente, la traductológica. lingüística.

2.1. La política del multilingüismo desde una perspectiva

La Unión Europea es una comunidad política de 27 Estados europeos que se rige en un marco jurídico-institucional propio en el que se reconocen como oficiales un total de 23 lenguas $^{19}$. De hecho, este régimen lingüístico es una de las principales características y señas de identidad que hacen de la UE una organización supranacional, que no internacional, como es el caso, entre otros, de la Organización de las Naciones Unidas (ONU), el Consejo de Europa o la Organización del Tratado del Atlántico Norte (OTAN), que utilizan un número limitado de lenguas para comunicarse entre sus miembros. Las resoluciones de estas organizaciones internacionales van dirigidas sólo a los gobiernos mientras que las decisiones que se toman en las instituciones de la UE afectan a menudo a ciudadanos o empresas ${ }^{20}$. La siguiente tabla, en la que se recogen el número de lenguas oficiales de las principales organizaciones gubernamentales de ámbito internacional, ofrece una clara muestra del peso que la política lingüística tiene en la UE con respecto al resto de organizaciones:

\footnotetext{
${ }^{19}$ Las 23 lenguas oficiales de la UE son: alemán, búlgaro, checo, danés, eslovaco, esloveno, español, estonio, finés, francés, griego, húngaro, inglés, irlandés, italiano, letón, lituano, maltés, neerlandés, polaco, portugués, rumano y sueco.

${ }^{20}$ BRACKENIERS, Eduard, "Europe without frontiers and the language challenge", en Terminologie \& Traduction. núm. 2, Luxemburgo, Oficina de Publicaciones oficiales de las Comunidades Europeas, 1995: 13.
}

Futhark 7 (2012)

Castellano, Análisis del concepto, 43-84

ISSN 1886-9300 


\begin{tabular}{|l|c|}
\hline \multicolumn{1}{|c|}{ Institución } & $\begin{array}{c}\text { Número de } \\
\text { lenguas oficiales }\end{array}$ \\
\hline Unión Europea & 23 \\
\hline Organización de las Naciones Unidas & 6 \\
\hline Unión Africana & $4(6)^{21}$ \\
\hline MERCOSUR & 4 \\
\hline Organización Mundial del Comercio & 3 \\
\hline Consejo de Europa & 2 \\
\hline OTAN & 2 \\
\hline
\end{tabular}

El marco jurídico en el que surge y se desarrolla la política multilingüe comunitaria encuentra su principio inmediato en el artículo 190 del Tratado constitutivo de la Comunidad Europea de la Energía Atómica (CEEA - EURATOM): «El régimen lingüístico de las instituciones de la Comunidad será fijado por el Consejo, por unanimidad, sin prejuicio de las disposiciones previstas en el reglamento del Tribunal de Justicia". De este modo, se otorga al Consejo autoridad para establecer el régimen lingüístico comunitario, y así fue. El Reglamento 1/1958 de este órgano reconoce en el art. 1 que «las lenguas oficiales y las lenguas de trabajo de las instituciones de la Comunidad serán el alemán, el francés, el italiano y el neerlandés", aunque, hasta llegar a la actual cifra de 23, este articulado se ha visto modificado conforme se han adherido nuevos Estados a las Comunidades Europeas ${ }^{22}$.

\footnotetext{
${ }^{21}$ Las lenguas oficiales de la Unión Africana (UA) han sido siempre el árabe, el francés, el inglés y el portugués. Tras la Cumbre anual de 2004 se añadirían dos lenguas más: español y suajili. Aunque la incorporación total de estas dos nuevas lenguas no se ha realizado aún.

${ }^{22}$ A partir de 1973 el danés y el inglés pasan a ser lenguas oficiales; al igual que en 1981 lo fue el griego y en 1986 el español y el portugués. En 1995 se suman dos nuevas lenguas, el finlandés y el sueco, con los que se alcanzada un total de once lenguas oficiales en la llamada Europa de los 15. Cerca de una década más tarde, en 2004, se lleva a cabo la mayor ampliación comunitaria a un total de diez nuevos países, cuyas lenguas oficiales pasarían también a ser las comunitarias: checo, eslovaco, esloveno, estonio, húngaro, letón, lituano, maltés y polaco. Tras la adhesión en 2007 de Bulgaria y Rumanía, tanto búlgaro como rumano se convierten en lenguas oficiales, sin olvidar el irlandés.
}

Futhark 7 (2012)

Castellano, Análisis del concepto, 43-84

ISSN 1886-9300 
El carácter oficial otorga a cada una de las 23 lenguas la misma validez y autenticidad en cualquier texto, escrito $u$ oral, de las instituciones de la Unión. Se perfila, por tanto, un contexto multilingüe donde los servicios lingüísticos ostentarán una función protagonista que queda bien expresada, entre otras posibles, por $\mathrm{M}$. Janssen y $M$. van Campenhoudt «Aborder el multilinguisme et le problème de l'équivalence des termes conduit à ressentir davantage le besoin d'une prise en compte du fait polysémique» ${ }^{23}$.

El primer hecho histórico que pone en marcha la política del multilingüismo surge de la necesidad de asegurar una "equivalencia" en la validez y autenticidad de los documentos que integran la jurisprudencia de la Comunidad Europea del Carbón y el Acero. Sobre esta cuestión, C. Heynold ${ }^{24}$ afirma lo siguiente:

La première organisation européenne, à savoir la Communauté européenne du charbon et de l'acier (CECA), créée en 1951, a privilégié le français (...). La mise en place de la Cour d'arbitrage prévue par le Traité de Paris a fait surgir la nécessité d'assurer une équivalence de la jurisprudence dans les quatre langues (le français, l'allemand, l'italien et le néerlandais) des six pays membres de la CECA. Ainsi, dès le démarrage de la première communauté, il est devenu évident qu'afin que nul n'ignore la loi, il n'est pas possible d'imposer celle-ci dans une langue étrangère.

Les pères fondateurs de la deuxième organisation européenne, la Communauté économique européenne (CEE), en ont tiré l'enseignement qu'il valait mieux rédiger tout de suite le texte qui devait régir son fonctionnement, c'est-à-dire le Traité de Rome, dans les quatre langues officielles, chaque version faisant également foi (article 247).

La primera organización europea, a saber la Comunidad Europea del Carbón y el Acero (CECA), creada en 1951, privilegió el francés (...). La creación del

\footnotetext{
23 JANSSEN, Maarten; VAN CAMPENHOUdT, Marc, "Terminologie traductive et représentation des connaissances : I'usage des relations hyponymiques", en Langages, núm. 157, 2005: 64.

${ }^{24}$ HEYNOLD, Christian, "L'Union européenne: Jardin d'Éden ou Tour de Babel ?", en Terminologie \& Traduction, núm. 3, Luxemburgo, Oficina de Publicaciones oficiales de las Comunidades Europeas, 1999: 5.
}

Futhark 7 (2012)

Castellano, Análisis del concepto, 43-84

ISSN 1886-9300 
Tribunal de arbitraje ${ }^{25}$ previsto por el Tratado de París hizo surgir la necesidad de asegurar una equivalencia de la jurisprudencia en las cuatro lenguas (el francés, el alemán, el italiano y el neerlandés) de los seis países miembros de la CECA. Así, desde la puesta en marcha de la primera comunidad, es evidente que para que nadie ignore la ley, resulta imposible imponer lo anterior en una lengua extranjera.

Los padres fundadores de la segunda organización europea, la Comunidad Económica Europea (CEE), aprendieron la lección de que sería mejor redactar al mismo tiempo el texto que iba a regir su funcionamiento, es decir, el Tratado de Roma, en las cuatro lenguas oficiales, haciendo igualmente fe cada versión (traducción del autor).

Se constata, de acuerdo con lo anterior, que el motivo por el que surge la política del multilingüismo en el seno de las primeras instituciones comunitarias se debe a la cuestión de la "equivalencia» que se precisa de los documentos que debían aplicarse a los Estados miembros. Aunque es cierto que el francés siguió siendo durante los siguientes años la lingua franca de las Comunidades y que quizás es temprano aún para hablar propiamente de multilingüismo, pues más bien se trataba de una situación de plurilingüismo, en la que la mayoría de los funcionarios conocían las cuatro lenguas oficiales y trabajaban en temáticas muy limitadas, por lo que resultaba mucho más fácil especializarse en un ámbito concreto, dominar su terminología e incluso expresarse en varias de las lenguas oficiales ${ }^{26}$. Por tanto, se puede decir que el multilingüismo se ha establecido como régimen lingüístico de forma progresiva, a la misma vez que las Comunidades Europeas ampliaban el número de Estados miembros y de lenguas oficiales.

A pesar de que todas las lenguas oficiales de los Estados miembros lo son de facto, en la Unión se pueden distinguir dos grupos en este sentido: las lenguas oficiales, como ya hemos visto, y

\footnotetext{
${ }^{25}$ Seguramente C. Heynold se refería a la Cour de justice en vez de Cour d'arbitrage, ya que éste nunca existió. Puede, no obstante, que se refiriese a este tribunal como institución responsable de realizar la labor jurídica del arbitraje entre los países miembros.

${ }^{26}$ BRACKENIERS, Eduard, "Europe without frontiers and the language challenge", en Terminologie \& Traduction. núm. 2, Luxemburgo, Oficina de Publicaciones oficiales de las Comunidades Europeas, 1995: 14.
}

Futhark 7 (2012)

Castellano, Análisis del concepto, 43-84

ISSN 1886-9300 
las lenguas de trabajo. Esta división encuentra su origen también en el citado Reglamento 1/1958 del Consejo, cuyos artículos 4 y 5 dicen que «los reglamentos y demás textos de alcance general se redactarán en las cuatro lenguas oficiales» y «El Diario Oficial de la Comunidad se publicará en las cuatro lenguas oficiales ${ }^{27}$; mientras que el artículo 6 recoge que «las instituciones podrás determinar las modalidades de aplicación de este régimen lingüístico en sus reglamentos internos», y el artículo 7 añade que "el régimen lingüístico del procedimiento del Tribunal de Justicia se determinará en el reglamento de procedimiento de éste». Por tanto, no es de extrañar que determinados órganos prefieran trabajar a nivel intrainstitucional con determinadas lenguas debido al peso social, histórico o político que éstas presentan. De esto se puede deducir que no siempre resulta aplicable un mismo régimen lingüístico equitativo en todas las lenguas oficiales. Cierto es que, por lo general, se traduce a todas estas lenguas la información esencial que implica a la ciudadanía europea -tratados, actos legislativos, declaraciones, directivas, reglamentos, sentencias, etc. ${ }^{28}$ aunque aquello que concierne al funcionamiento interno de cada institución notas, informes, comunicados o circulares, entre otros- es competencia propia del órgano en cuestión y son susceptibles de redactarse en, o traducirse a, las lenguas que dicha institución estime conveniente.

El Parlamento Europeo es la única institución que trabaja ampliamente con cualquier lengua y con distintas combinatorias lingüísticas debido a que los eurodiputados provienen de todos los Estados miembros por lo que pueden expresarse, a nivel oral y escrito, en sus lenguas maternas, o bien precisar o emitir cualquier tipo de documentación en una u otra lengua. En lo que respecta al Consejo de la UE, sus lenguas de trabajo habituales son el alemán, el francés y el inglés; esto se debe, sobre todo, a que son las lenguas de funcionamiento del Comité de Representantes Permanentes (Coreper), por lo general, especialistas en diferentes materias que hacen uso de estos idiomas para coordinar el trabajo

\footnotetext{
${ }^{27}$ Entiéndase que el número de lenguas aumentará a seis, siete, nueve, once y veinte, hasta 23 , conforme se modifica el Reglamento 1/1958 del Consejo, debido a la adhesión de nuevos Estados miembros.

${ }^{28}$ FORREST, Alan, "The challenge of languages in Europe", en Terminologie \& Traduction, núm. 3, Luxemburgo: Oficina de Publicaciones oficiales de las Comunidades Europeas, 1998: 105-106.

Futhark 7 (2012)

Castellano, Análisis del concepto, 43-84
}

ISSN 1886-9300 
entre las delegaciones de todos los Estados ${ }^{29}$. En cuanto al brazo ejecutivo de la UE, la Comisión Europea, las lenguas de trabajo son por igual: alemán, francés e inglés. En el caso del Tribunal de Justicia de la UE, a pesar de que su reglamento recoja que todas las lenguas oficiales son lenguas de procedimiento, es decir, que todas las sentencias deben estar publicadas en las 23 lenguas, lo cierto es a nivel interno, la lengua de trabajo por antonomasia es el francés.

En relación con lo anterior, cabe destacar también la prevalencia, aunque nunca en términos oficiales, de una lingua franca a nivel interno. En principio y hasta finales de la década de los años 80 del pasado siglo, el francés mantuvo un estatus privilegiado por varios motivos: existía una mayoría de países francófonos respecto al resto hasta la fecha (Bélgica, Francia y Luxemburgo), las sedes institucionales se encuentran en ciudades francófonas, a saber, Bruselas (Comisión, Consejo, Parlamento, Comité de las Regiones, Comité Económico y Social, etc.), Luxemburgo (Tribunal de Justicia, Tribunal de Cuentas, Secretaría General del Parlamento, etc.) y Estrasburgo (Parlamento y Defensor del Pueblo) y, entre otros motivos, el francés ha sido siempre lengua de redacción originaria de los tratados constitutivos, así como del resto de los principales documentos institucionales comunitarios. Pero a partir de la década de los años 90, la balanza se inclina a favor de la lengua inglesa ${ }^{30}$. Son varios los factores que explican este cambio, como, por ejemplo el proceso cada vez mayor de globalización, la hegemonía estadounidense y asiática en los asuntos económicos a nivel internacional, la desaparición del bloque soviético, en detrimento del alemán y el ruso, entre otros factores ${ }^{31}$. A nivel comunitario, las adhesiones de 1995, 2004 y 2007 terminaron por otorgar al inglés un predominio superior al del francés ya que estos países, en su mayoría de extensión mucho más reducida que los países de la Europa de los 15 y cuyas lenguas son, exceptuando algunos casos,

29 Moratinos JOHnStON, Sofía, "Multilingualism and EU Enlargement", en Terminologie \& Traduction, núm.3, Luxemburgo: Oficina de Publicaciones oficiales de las COmunidades Europeas, 2000: 26-34.

${ }^{30}$ Con esto no se quiere demeritar el valor y la presencia que la lengua inglesa ha tenido en la construcción europea desde un principio, pues, mucho antes de que en 1973 pasara a ser lengua oficial, ya se encontraban unidades de inglés en los servicios lingüísticos de las primitivas Comunidades Europeas.

${ }^{31}$ MÚRIAS, Augusto, "A propósito do multilinguismo sob especial consideração da língua portuguesa", en Terminologie \& Traduction, núm. 1, Luxemburgo: Oficina de Publicaciones oficiales de las Comunidades Europeas, 1999: 59-60.

Futhark 7 (2012)

Castellano, Análisis del concepto, 43-84

ISSN $1886-9300$ 
minoritarias; encontraron en el inglés la vía rápida de mantener relaciones diplomáticas con los principales foros sociales y económicos tras la caída de la URSS.

El Ministerio de Justicia de Finlandia, país miembro desde 1995, comenzó a traducir al finlandés, en torno a 1990, el acervo comunitario partiendo de las versiones en lengua inglesa, ya que ésta era la lengua oficial de la Asociación Europea de Libre Comercio (AELC, en inglés EFTA), de la que Finlandia era miembro desde 1985. No obstante, entre 1992 y 1993, el Ministerio optó por comenzar nuevamente la traducción de los documentos del acervo comunitario aunque, en esta ocasión, partiendo de la lengua francesa, ya que se llegó a la conclusión de que, puesto que, la mayoría de estos textos en versión inglesa eran a su vez traducciones de las versiones francesas, al traducir directamente de la lengua fuente principal se evitarían posibles ilegibilidades o malas interpretaciones $^{32}$. A esto resulta pertinente destacar las consideraciones vertidas por Susan Šarcevic sobre la preponderancia del inglés en los países de la Europa oriental y los escandinavos ${ }^{33}$ :

Like Croatia, it appears that most of the applicant states from Central Eastern Europe (CEE) have selected English as the primary source text for translations of the acquis. As in the Scandinavian countries, English has become by far the dominant foreign language in these countries. In the interest of guaranteeing reliability, certain factors should be taken into account when determining how many and which texts should be consulted in addition to the English authentic texts. Above all, it is necessary to keep in mind that the English authentic texts are translations in the majority of cases (...).

Como Croacia, al parecer la mayoría de los países candidatos de la Europa Central y Oriental (PECO) han elegido el inglés como el principal texto fuente para las traducciones del acervo. Al igual que los países escandinavos, el inglés se ha convertido de sobra en la lengua extranjera dominante en estos países. En interés de garantizar la fiabilidad, ciertos factores deberían tenerse en

\footnotetext{
${ }^{32}$ GAMBIER, Yves, "Mouvances eurolinguistiques. Cas de la Finlande", en BALLARD, Michel (ed.), Europe et traduction. Arras: Artois Presses Université. 1998: 296.

${ }^{33}$ ŠARCEVIC, Susan, "Preserving Multilingualism in an Enlarged European Union", en Terminologie \& Traduction, núm. 2, Luxemburgo, Oficina de Publicaciones oficiales de las Comunidades Europeas, 2001: 41-42.

Futhark 7 (2012)

Castellano, Análisis del concepto, 43-84
}

ISSN 1886-9300 


\begin{abstract}
consideración al determinar cuántos y qué textos deberían consultarse además de los textos auténticos ingleses. Sobre todo, es necesario no perder de vista que los textos auténticos en lengua inglesa son traducciones en la mayoría de los casos (...) (traducción del autor).
\end{abstract}

\title{
2.2. La perspectiva jurídica: el acervo comunitario
}

Otro factor que condiciona y delimita el concepto de equivalencia y su aplicación en este contexto institucional es el acervo comunitario, es decir, el compendio de tratados constituyentes o fundacionales, la legislación proveniente de los órganos, los actos o acuerdos adoptados por la Unión, así como la jurisprudencia que emana del Tribunal de Justicia (Derecho Comunitario). Puesto que debe ser aplicable y asumido por todos los Estados miembros, el concepto de equivalencia cobra en este sentido un doble valor, ya que éste deberá transmitirse tanto a nivel conceptual como a nivel lingüístico a las 23 lenguas oficiales, por lo que el equilibrio entre la denominación y el concepto del término en cuestión no sólo deberá afectar a las lenguas de manera particular, sino a todas en su conjunto; de tal modo que un mismo término sea aplicable y comprensible por igual en maltés, irlandés o neerlandés, indistintamente la cultura jurídica de sus respectivos países.

Sin embargo, la expresión «acervo comunitario» es en sí una clara muestra de la complejidad que el proyecto europeo supone a la hora de traducirse a todas las lenguas oficiales. El origen de este término proviene del francés acquis communautaire, aunque su traducción varía tanto de una lengua a otra como de un tipo de documento a otro y cabe destacar que en muchos casos se mantiene el original francés, bien para asegurar de este modo la equivalencia con respecto a la fórmula original, bien porque la cultura jurídica de la lengua receptora no contempla una realidad similar o aproximada, o incluso porque la lengua de llegada pertenece a una familia lingüística lejana con respecto a la romance a la que pertenece el francés. A continuación, se muestra el término "acervo comunitario" en las 23 lenguas oficiales, por una parte la versión más habitual recogida por la extinta base de datos CELEX ${ }^{34}$,

\footnotetext{
${ }^{34}$ PeYró, Francisco, "Le "qui-dit-quoi" de l'acquis communautaire", en Terminologie \& Traduction, núm. 2, Luxemburgo, Oficina de Publicaciones oficiales de las Comunidades Europeas, 1999: 57-68.
}

Futhark 7 (2012)

Castellano, Análisis del concepto, 43-84

ISSN 1886-9300 
por otra la versión que recoge el glosario de legislación de la Unión Europe ${ }^{35}$ en sus formas habituales, aunque esto no significa que en un determinado contexto existan variantes en una misma lengua ${ }^{36}$ :

\begin{tabular}{|c|c|c|}
\hline Lengua & $\begin{array}{l}\text { CELEX (Europa de los } \\
\text { 15) }\end{array}$ & $\begin{array}{l}\text { EUROPA (Europa de } \\
\text { los 27) }\end{array}$ \\
\hline alemán & $\begin{array}{l}\text { Gemeinschaftlicher } \\
\text { Besitzstand }\end{array}$ & $\begin{array}{l}\text { Acquis } \\
\text { communautaire, } \\
\text { Gemeinsamer } \\
\text { Besitzstand }\end{array}$ \\
\hline búlgaro & - & $\begin{array}{l}\text { на достиженията на } \\
\text { правото на EC }\end{array}$ \\
\hline checo & - & $\begin{array}{l}\text { acquis } \\
\text { communautaire, } \\
\text { komunitární acquis }\end{array}$ \\
\hline danés & gældende fællesskabsret & $\begin{array}{l}\text { EU-retten, acquis } \\
\text { communautaire }\end{array}$ \\
\hline eslovaco & - & $\begin{array}{l}\text { acquis } \\
\text { communautaire }\end{array}$ \\
\hline esloveno & - & $\begin{array}{l}\text { acquis } \\
\text { communautaire } \\
\text { (pravni red EU) }^{37}\end{array}$ \\
\hline español & acervo comunitario & acervo comunitario \\
\hline estonio & - & $\begin{array}{l}\text { ühenduse õigustik, } \\
\text { acquis }\end{array}$ \\
\hline finlandés & yhteisön säännöstö & $\begin{array}{l}\text { acquis, acquis } \\
\text { communautaire }\end{array}$ \\
\hline francés & acquis communautaire & $\begin{array}{l}\text { acquis } \\
\text { communautaire }\end{array}$ \\
\hline griego & 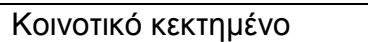 & 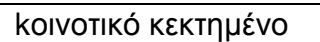 \\
\hline
\end{tabular}

${ }^{35} \mathrm{http}: / /$ europa.eu/abc/eurojargon/index_es.htm [Consultado el 29 de enero de 2011]

${ }_{36}$ Las versiones en búlgaro, irlandés y rumano no quedan recogidas en el recurso anterior, por lo que han sido extraídos de legislación vigente, concretamente del Reglamento (UE) $n{ }^{\circ} 540 / 2010$ del Parlamento Europeo y del Consejo, de 16 de junio de 2010 , que modifica el Reglamento (CE) $n{ }^{\circ} 1085 / 2006$ del Consejo, por el que se establece un Instrumento de Ayuda Preadhesión (IPA).

${ }^{37}$ Indica textualmente «acquis de la UE».

Futhark 7 (2012)

Castellano, Análisis del concepto, 43-84

ISSN 1886-9300 


\begin{tabular}{|c|c|c|}
\hline húngaro & - & $\begin{array}{l}\text { közösségi vívmányok, } \\
\text { „acquis } \\
\text { communautaires” }\end{array}$ \\
\hline inglés & «acquis communautaire» & $\begin{array}{l}\text { Communityacquis, } \\
\text { Acquis } \\
\text { communautaire }\end{array}$ \\
\hline irlandés & - & $\begin{array}{l}\text { acquis } \\
\text { communautaire }\end{array}$ \\
\hline italiano & acquis comunitario & $\begin{array}{l}\text { acquis comunitario, } \\
\text { «aquis» comunitario }\end{array}$ \\
\hline letón & - & $\begin{array}{l}\text { acquis } \\
\text { communautaire }\end{array}$ \\
\hline lituano & - & $\begin{array}{l}\text { acquis } \\
\text { communautaire }\end{array}$ \\
\hline maltés & - & $\begin{array}{l}\text { Acquis } \\
\text { Communautaire }\end{array}$ \\
\hline neerlandés & $\begin{array}{l}\text { communautaire } \\
\text { verwovenheden, acquis } \\
\text { communautaire }\end{array}$ & $\begin{array}{l}\text { acquis } \\
\text { communautaire }\end{array}$ \\
\hline polaco & - & $\begin{array}{l}\text { wspólnotowy dorobek } \\
\text { prawny (nazywany } \\
\text { także z francuskiego } \\
\text { Acquis } \\
\text { communautaire) }\end{array}$ \\
\hline portugués & Acervo comunitário & acervo comunitário \\
\hline rumano & - & acquis comunitar \\
\hline sueco & Gemenskapens regelverk & $\begin{array}{l}\text { Gemenskapens } \\
\text { regelverk }\end{array}$ \\
\hline
\end{tabular}

Esto es un claro ejemplo del reto que supone transmitir a un total de 27 Estados, cada uno de ellos con una legislación y una jurisprudencia particular, una nueva legislación y jurisprudencia que debe ser igual para todos y, además, multilingüe. De hecho, los pilares del acervo comunitario se crean a partir del acuerdo que los Estados miembros toman con la firma de los tratados y demás

${ }^{38}$ Indica textualmente «también conocido como acquis communautaire en francés».

Futhark 7 (2012)

Castellano, Análisis del concepto, 43-84

ISSN 1886-9300 
documentos vinculantes; éste se desarrolla y resulta aplicable a sus propios creadores, o dicho de otro modo, el acervo comunitario -del que destaca sobre todo el Derecho Comunitario- se transmite tanto a legislación nacional como a los derechos nacionales. Se trata, pues, de un circuito cíclico en el que se generan conceptos propios de la UE y nuevos para los Estados miembros, quienes deberán adoptarlos a nivel particular. K. Gidová ${ }^{39}$ denomina a esta realidad «Sistema de Referencia Múltiple» y la ilustra con el esquema que sigue:

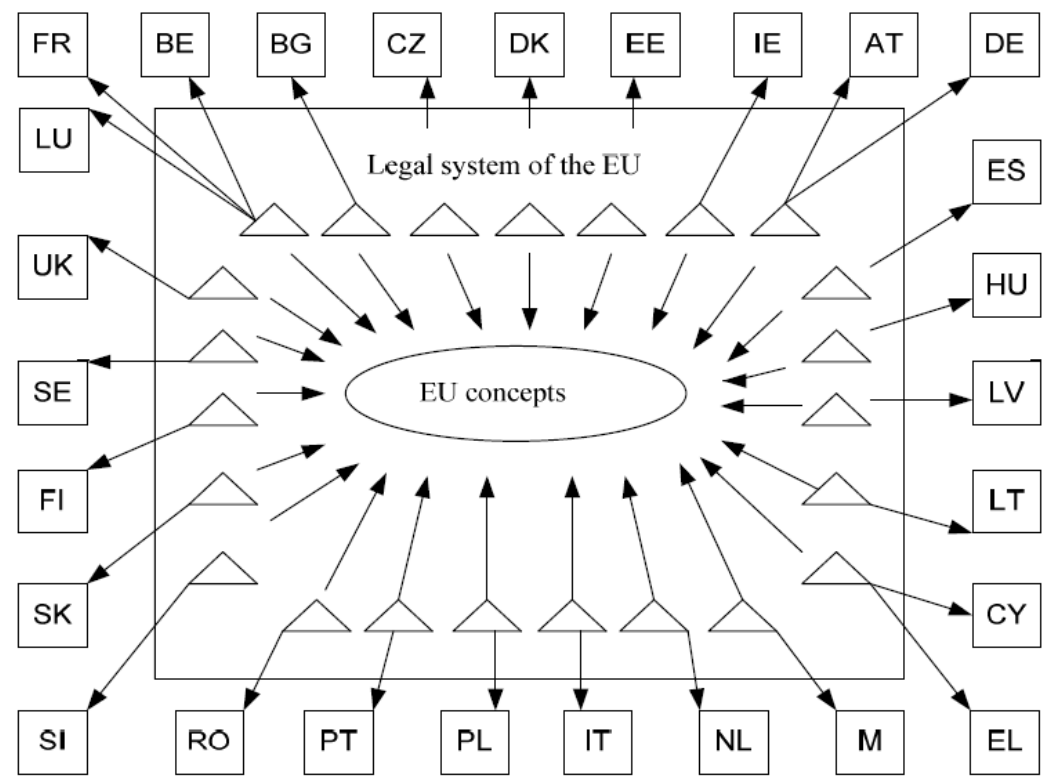

El Sistema de Referencia Múltiple muestra el circuito comentado anteriormente. Los 23 triángulos representan las lenguas oficiales -inscritas en el marco jurídico comunitario- que son a su vez, instrumentos a través de los que se transmiten los conceptos de la UE al resto de sistemas nacionales, que en este esquema son los cuadrados que quedan fuera del marco jurídico. Esta terminología es autónoma ya que está constituida por conceptos propios de la Unión

39 GIDOVA, Klaudia, "EU Translation as the Language of a Reunited Europe Reconsidered", en FERENČík, Milan; HORVÁtH, Juraj (eds.), Language, Literature and Culture in a Changing Transatlantic World, 2009: 150. Recurso disponible en < http://www.pulib.sk/elpub2/FF/Ferencik2/> (Fecha de consulta: 30 de enero de 2011).

Futhark 7 (2012)

Castellano, Análisis del concepto, 43-84

ISSN $1886-9300$ 
Europea, además, al mismo tiempo ésta debe ser uniforme y equivalente en todas las lenguas oficiales, por lo que cada Estado deberá aplicarla directamente y sin ninguna alteración, lo cual no exime de que en ocasiones la labor de traducción sea ardua e incluso se preste a críticas. Por ejemplo, N. Buchin y G. Haller estudian la complejidad que supone la traducción del término alemán Mitbestimmung al resto de lenguas oficiales -en aquel momento once- en el contexto de un informe del Parlamento Europeo sobre los sistemas europeos de participación laboral ${ }^{40}$ :

Nous nous proposons d'illustrer le problème de traduction posé par le terme Mitbestimmung qui correspond à une réalité économique et juridique dans un État membre (mais peut revêtir des formes différentes), et pour lequel trouver une équivalence tient en quelque sorte de l'utopie en raison de la diversité des structures des entreprises et de modes de représentation ou de participation des travailleurs au sein de celles-ci. Ajoutons que les termes qui, dans les autres langues, sont susceptibles d'entrer en ligne de compte comme équivalentes (par exemple participation ou cogestion en français) n'ont pas toujours des contours bien définis. Précisons également que le terme qui pose problème apparaît dans une résolution du Parlement européen où il est fait référence à d'autres documents (...) n'utilisant pas la même terminologie.

Nos proponemos ilustrar el problema de traducción planteado por el término Mitbestimmung que corresponde con una realidad económica y jurídica en un Estado miembro (pero puede aparecer con diferentes formas), y para el que encontrar una equivalencia supone en cierto modo la utopía por motivo de la diversidad de las estructuras de las empresas y de las formas de representación $o$ de participación de los trabajadores en las anteriores. Añadimos que los términos que, en las otras lenguas, son susceptibles de considerarse como equivalentes (por ejemplo participation o cogestion en francés) no tienen siempre límites bien definidos. Asimismo precisamos que el término que plantea problema aparece en una resolución del Parlamento Europeo donde se hace referencia a otros documentos (...) sin utilizar la misma terminología (traducción del autor).

40 Buchin, Nicole; HalleR, Gudrun, "Implications politiques des choix terminologiques", en Terminologie \& Traduction, núm. 1, Luxemburgo, Oficina de Publicaciones oficiales de las Comunidades Europeas, 1999: 14.

Futhark 7 (2012) Castellano, Análisis del concepto, 43-84

ISSN 1886-9300 
De hecho, las soluciones que se proponen para el caso anterior vienen condicionadas en ocasiones por determinaciones políticas. Aunque este tipo de casos suele ser muchísimo más frecuente en los documentos no vinculantes de la Unión Europea, tales como manifiestos, declaraciones, etc. Conocido es el caso de la Declaración de Berlín ${ }^{41}$ y su traducción a lengua inglesa, la cual presentaba menos énfasis en la terminología utilizada. Sobre este asunto, cabe destacar también las consideraciones de E. Magiera ${ }^{42}$ respecto a las versiones inglesa, francesa y polaca con respecto al original alemán de la citada declaración. En su estudio, la autora se percata de las abundantes variaciones de significado relacionadas con los posicionamientos políticos de los Estados a los que corresponden una u otra lengua en cuestión.

\subsection{La perspectiva traductológica}

El traductor, como profesional que es, debe contar con una serie de competencias específicas para abordar su labor. En este sentido, además de poseer un dominio absoluto de las lenguas implicadas en la traducción, éste tiene que ser un conocedor avezado en la materia sobre la que versa el texto especializado en cuestión. En lo que respecta al contexto de la Unión Europea, por la idiosincrasia que caracteriza a esta institución, las competencias que cualquier traductor -intérprete o terminólogo- necesita para el desempeño de su trabajo en los servicios lingüísticos comunitarios son mucho más precisas ${ }^{43}$ :

Bisogna considerare che il processo di traduzione politica in ambito comunitario è -anche se questo aspetto apparentemente banale (...)- un'attività che non si limita alla mera trasposizione linguistica, ma che sovente ingloba un

\footnotetext{
${ }^{41}$ Se trata del manifiesto realizado por el Consejo de la Unión Europa el 25 de marzo de 2007, fecha en la que se cumplían 50 años de la firma de los Tratados de Roma. El hecho de que se realizara en Berlín se debe a que Alemania era el país que acogía la presidencia de turno de aquel entonces.

42 MAGIERA, Ewa, "La traduction comme dialogue et son rôle particulier au sein des institutions européennes", en KNECHCIAK, Olivier (dir.), Langues européennes en dialogue, Collection Euryopa vol. 62, 2009, págs. 9-21. Recurso disponible en $<$ tttp://www.unige.ch/ieug/publications/euryopa/Knechciak.pdf> (Fecha de consulta: 25 de enero de 2011).

${ }^{43}$ Cosmal, Domenico, "L'idioletto politico delle istituzioni europee: caratteristiche e approcci traduttivi", en Terminologie \& Traduction, núm. 2, Luxemburgo, Oficina de Publicaciones oficiales de las Comundiades Europeas, 2000: 15.
}

Futhark 7 (2012)

Castellano, Análisis del concepto, 43-84

ISSN 1886-9300 

processo di adeguamento, chiarimento e delucidazione, per
non dire di interpretazione linguistica tout court del testo
originale.

Debemos tener en cuenta que el proceso de traducción política en ámbito comunitario es -aun cuando este aspecto resulta aparentemente banal (...)- una actividad que no se limita a la mera transposición lingüística, sino que a menudo incluye un proceso de adaptación, explicación y aclaración, por no decir de interpretación lingüística sólo del texto original (traducción del autor).

Por otra parte, las competencias traductoras deben coordinarse con las de los especialistas y técnicos que trabajan en las instituciones, por lo que resulta difícil establecer el límite concreto sobre hasta qué punto el traductor, como profesional, puede o no intervenir en el nuevo texto traducido. De hecho, de acuerdo con el criterio de F. J. Muñoz Martín y M. Valdivieso Blanco ${ }^{44}$, los textos especializados que se redactan y traducen a nivel institucional de la UE -en esta ocasión, citan los pertenecientes al Consejo de la UEprecisan de una serie de contenidos especializados o técnicos, con las correspondientes expresiones del ámbito de especialidad, así como de una formulación lingüística y de una validación jurídica. De este modo, presentan tres competencias, a saber, técnica (CT), lingüística (CL) y jurídica (CJ) cuya convergencia final aporta la citada especialización a los textos $(T)$ de ámbito institucional de la UE. A continuación se muestra el esquema en el que F. J. Muñoz Martín y M. Valdivieso representan esto anterior:

\footnotetext{
${ }^{44}$ Muñoz Martín, Francisco Javier; Valdivieso Blanco, María, "Traductores y especialistas en la Unión Europea. Hacia el binomio integrador", en Tonos digital: Revista electrónica de estudios filológicos, núm. 12, 2006. Recurso disponible en $<$ http://www.um.es/tonosdigital/znum12/subs/indice/lndiceTonos.htm> (Fecha de consulta: 31 de enero de 2011).

Castellano, Análisis del concepto, 43-84
}

Futhark 7 (2012)

ISSN 1886-9300 


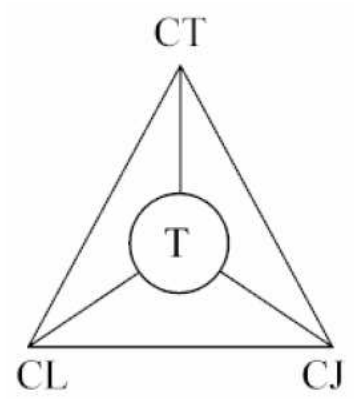

$$
\begin{aligned}
& \mathrm{CT}=\text { competencia técnica } \\
& \mathrm{CL}=\text { competencia lingüística } \\
& \mathrm{CJ}=\text { competencia jurídica } \\
& \mathrm{T}=\text { texto traducido }
\end{aligned}
$$

Estos autores proponen, por su parte, un trinomio funcional donde tanto especialistas, como traductores y juristas son protagonistas de la elaboración del texto, entendido siempre como instrumento. Igualmente, detallan que quizás la interacción entre especialistas y traductores debiera ser mayor e incluso simultánea para aprovechar las competencias que ambos ofrecen.

Un elemento fundamental en todo acto traductor es aquella unidad que va a ser traducida, es decir, el texto. Pero ¿qué tipo de textos se traducen en el seno de las instituciones de la Unión Europea? Debido al carácter transversal que tiene el ámbito competencial de la UE, los textos comunitarios responden a diferentes tipos tanto en forma como en temática. Se puede diferenciar, según R. Goffin ${ }^{45}$, principalmente, textos legislativos (relativos al Derecho comunitario, tanto el originario como el derivado), textos administrativos (sobre el funcionamiento y la orgánica de la Unión), textos políticos (provenientes de los principales responsables institucionales, manifiestos, etc.), textos técnicos y, por supuesto, textos jurídicos ${ }^{46}$. Además, R. Goffin matiza que, aunque, en principio todos ellos provengan de diferentes órganos y traten sobre temas dispares, se enmarcan en un contexto idéntico y comparten, además del espacio, una terminología común que les es propia ${ }^{47}$ : «La législation communautaire a engendré des notions nouvelles, "méta-nationales", sans équivalence exacte dans

\footnotetext{
45 Goffin, Roger, "L'Europe en neuf langues : champ d'affrontements et ferment d'intégration linguistiques", en Meta : journal des traducteurs / Meta: Translators' Journal, vol. 35, núm. 1, 1990: 14.

${ }^{46}$ Se trata de una especialización que R. Goffin (1990: 14) no contempla.

${ }^{47}$ Véase nota a pie de página 45.

Futhark 7 (2012)

Castellano, Análisis del concepto, 43-84
}

ISSN 1886-9300 
aucun pays et dans aucune des langues» ${ }^{48}$. Por tanto, desde un enfoque traductológico como el que aquí interesa, y salvando las particularidades que puedan surgir, resulta incluso ventajoso la existencia de tales nociones meta-nacionales que son comunes a todos las lenguas, y por ende, equivalentes.

Una de las principales características en este tipo de textos es la simetría que existe en todas las versiones lingüísticas respecto a los apartados, párrafos e incluso oraciones. Esto se pone de manifiesto en la obligatoriedad que se tiene a la hora de traducir de mantener los signos de puntuación por igual sea cual sea la lengua a la que se traduzca. La razón que motiva esta particular equivalencia "sintáctica» responde a cuestiones puramente técnicas, puesto que a la hora de tener que documentarse sobre un determinado aspecto o bien tener que modificar incluso el contenido de un «instrumento", como un reglamento o una directiva, resulta más sencillo y rápido hacerlo, teniendo en cuenta qué oración, fragmento o párrafo es ya que sea cual sea la lengua, su versión tendrá una extensión, puntuación y posición aproximadas en el texto.

De lo contrario, esta simetría puede suponer también un lastre a la hora de traducir, puesto que no todas las lenguas tienen los mismos mecanismos de representación conceptual, de ordenación de textual o de estructuración sintáctica. Así que en ocasiones para determinados hablantes de una lengua, el texto institucional de la Unión Europea podría parecer una «traducción» más que una versión lingüística:

[ES] K. Considerando que el Tratado de Lisboa introduce un enfoque nuevo y global para la acción exterior de la Unión - aunque con mecanismos específicos para la toma de decisiones en el ámbito de la Política Exterior y de Seguridad Común (PESC) - así como la creación del doble puesto de Vicepresidente de la Comisión (Alto Representante), que contará con el apoyo de un servicio especial para la acción exterior como elemento clave para que este nuevo enfoque integrado sea operativo, (...).

[FR] K. considérant que le traité de Lisbonne introduit une approche nouvelle et plus large de l'action extérieure de I'Union - bien qu'il prévoie des mécanismes de prise de

\footnotetext{
48 «La legislación comunitaria ha engendrado nociones nuevas, "meta-nacionales", sin equivalencia exacta en ningún país y en ninguna de las lenguas". (Traducción del autor).
}

Futhark 7 (2012)

Castellano, Análisis del concepto, 43-84

ISSN 1886-9300 
décision particuliers pour les questions liées à la politique étrangère et de sécurité commune (PESC) - et crée un poste "à deux casquettes" de vice-président de la Commission (haut représentant), qui sera assisté d'un service spécial pour l'action extérieure, qui constitue l'élément essentiel pour rendre cette nouvelle méthode intégrée efficace, (...).

[DE] K. unter Hinweis darauf, dass mit dem Vertrag von Lissabon ein neuer und umfassender Ansatz für das auswärtige Handeln der Union eingeführt wird - wenn auch mit spezifischen Mechanismen für die Beschlussfassung in Fragen, die sich auf die gemeinsame Außen- und Sicherheitspolitik (GASP) beziehen - und gleichzeitig mit einer "Doppelfunktion" ausgestattete Amt des Vizepräsidenten der Kommission (Hoher Vertreter) geschaffen wird, der von einem besonderen Auswärtigen Dienst als dem Schlüsselelement unterstützt wird, das diesen neuen und integrierten Ansatz operationell macht, (...).

[EN] K. whereas the Treaty of Lisbon introduces a new and comprehensive approach to the external action of the Union - albeit with specific mechanisms for decisionmaking in matters relating to the Common Foreign and Security Policy (CFSP) - as well as creating the "doublehatted" post of Vice-President of the Commission (High Representative) supported by a special external service as the key element rendering this new and integrated approach operative, (...).

Como se puede apreciar en los cuatro fragmentos anteriores $^{49}$, la simetría que ofrecen tanto en extensión como en formulaciones es prácticamente similar. Destacan, además, las siglas en sus correspondientes lenguas, los guiones o el uso de paréntesis y cargos institucionales. Sin embargo, en lo que respecta a la lengua inglesa, por ejemplo, resulta ser una oración muy extensa para la sintaxis habitual de este idioma; por lo que podría suponerse que quizás no fuera la versión inglesa la fuente original de este documento. Resulta, pues, que la elaboración de los documentos institucionales de la Unión Europea es compleja,

\footnotetext{
${ }^{49}$ Los cuatro fragmentos se corresponden con el apartado $\mathrm{K}$ de la Resolución del Parlamento Europeo, de 7 de mayo de 2009, sobre las repercusiones del Tratado de Lisboa en la evolución del equilibrio institucional en la Unión Europea (2008/2073(INI)), en sus versiones española, francesa, alemana e inglesa.
}

Futhark 7 (2012)

Castellano, Análisis del concepto, 43-84

ISSN 1886-9300 
variante dependiendo de la institución de donde proceda el texto, y en ocasiones enrevesada ${ }^{50}$ :

What makes these texts difficult to process is their tortuous progress, involving several different services and several different political levels, generating several successive versions and repeated translation of nuances and details (...).

Aquello que hace a estos textos difíciles de procesar es su tortuoso desarrollo, en el que participan varios servicios distintos así como varios niveles políticos diferentes, que generan numerosas versiones sucesivas y una traducción repetida de matices y detalles (...) (traducción del autor).

Cada institución, como hemos visto en el epígrafe anterior, posee cierta autonomía a la hora de organizar su trabajo interno, por lo que resulta imposible poder ofrecer un circuito homogéneo de redacción, elaboración y traducción textual que sea aplicable a todo el conjunto de la Unión. De hecho, no existe ningún tipo de directrices metodológicas que el cuerpo de traductores, intérpretes o terminólogos de los servicios lingüísticos comunitarios deba aplicar; más bien, disponen de una amplia gama de herramientas para llevar a cabo sus tareas ${ }^{51}$. Además de las históricas bases de datos terminológicas como Eurodicautom, TIS, Euterpe o la actual IATE cuya actualización se realiza por los propios profesionales lingüísticos; disponen también de gestor de memorias de traducción (Trados) o incluso de métodos de trabajo como DocuCom. Éste consiste en un sistema de trabajo en red: cuando se tiene que modificar un texto ya existente o bien se tiene que realizar uno nuevo pero que mantiene una estructura textual similar a la de otro, se indica en el TO con color aquellas partes que serán objeto de modificación, traducción, revisión, etc. De este modo, el texto, indistintamente esté en una lengua u otra, será idéntico a excepción de los términos, expresiones, fechas o topónimos que sean objeto de cambio. Aunque, como ya se ha indicado, cada organismo tiene autonomía para organizar su servicio lingüístico de acuerdo con sus posibilidades. Sin embargo, en términos generales, sí podemos

\footnotetext{
${ }^{50}$ WAGNER, Emma; BECH, Svend; MARTínEZ, Jesús M, Translating for the European Union Institutions, Manchester, St. Jerome Publishing, 2002: 48.

${ }^{51}$ En el caso de la Comisión, destaca EURAMIS (European Advanced Multilingual Information Systems), proyecto que comienza a finales de los años 90 para incorporar todos los servicios lingüísticos como el ya citado sobre memorias de traducción, extractores terminológicos, sistemas de traducción automática Systran, portal único de acceso a las bases de datos terminológicas, etc.
}

Futhark 7 (2012)

Castellano, Análisis del concepto, 43-84

ISSN 1886-9300 
afirmar que el proceso traductor se mantiene paralelo a la producción de los mismos, por lo que en ocasiones se trabaja con traducciones que a su vez son traducciones de otras lenguas, de ahí el tortuous progress que define este proceso, característica inherente de la mayoría de los textos comunitarios.

En relación con el concepto de texto, se encuentran las nociones de texto origen (TO) y texto meta (TM), que en este ámbito son susceptibles de no aplicarse como tales, puesto que el principio de equivalencia lingüística que rige la actividad comunitaria contempla la existencia de versiones lingüísticas, todas iguales y equivalentes; ya que si se considerasen traducciones, existiría por mera lógica un TO en el que se inspiraría el resto y en este caso la lengua en la que estuviera redactada dicho TO se encentraría en una situación privilegiada contraria a lo recogido en el Reglamento 1/1958 del Consejo de la UE. Sin embargo, no deja de plantearse una situación paradójica, debido a que las versiones lingüísticas lo son a nivel oficial, aunque desde la perspectiva traductológica que aquí nos ocupa resulta indiscutible que el concepto de «versión lingüística» sea un eufemismo de «traducción» en el que interfiere nuevamente el factor político e institucional.

Este complejo panorama, en el que la traducción protagonista del multilingüismo- queda al margen, se podría decir incluso que ignorada, en pro de la igualdad de valor que todas las versiones lingüísticas tienen, pero que al mismo tiempo no podría existir sin esta labor de traslación. De hecho, como se ha indicado anteriormente, se podría decir que en realidad lo traducido no son textos, sino «instrumentos» institucionales que adoptan forma de texto, en diferentes lenguas, para ser aplicados e interpretados ${ }^{52}$. Asimismo, la ausencia de un TO claramente definido platea problemas tanto a nivel de documentación como de comparativa textual entre TO y TM, ambas herramientas habituales en la traducción. Sólo queda la posibilidad de comparar las versiones lingüísticas, todas ellas relacionadas entre sí, aunque siempre anónimas. Por lo que ¿se puede hablar entonces de traducción?

\footnotetext{
52 ŠARCEVIC, Susan, New Approach to Legal Translation, La Haya, Kluwer Law International, 1997: 112.

Futhark 7 (2012)

Castellano, Análisis del concepto, 43-84

ISSN 1886-9300
} 
Ante la inexistencia de un TO visible y accesible, $\mathrm{K}$. Koskinen $^{53}$ afirma que el concepto de TO sí existe sólo que se trata de un texto que se caracteriza por su inestabilidad así como por el difícil acceso que se tiene a él. Por lo que se podría «reconstruir» el texto, o textos, que dio origen al resto de versiones lingüística a partir del estudio comparativo de todas las traducciones. Esto sólo es posible gracias al fenómeno de la intertextualidad ya que existe una fuerte interacción entre todos los textos, a priori, equivalentes. A continuación se muestra, teniendo en cuenta lo estudiado en este trabajo hasta el momento, un ejemplo en el que se manifiesta la interconexión que existe a nivel textual:

[ES] Toda persona tiene derecho a disfrutar de la propiedad de los bienes que haya adquirido legalmente, a usarlos, a disponer de ellos y a legarlos. Nadie puede ser privado de su propiedad más que por causa de utilidad pública, en los casos y condiciones previstos en la ley y a cambio, en un tiempo razonable, de una justa indemnización por su pérdida. El uso de los bienes podrá regularse por ley en la medida en que resulte necesario para el interés general.

[FR] Toute personne a le droit de jouir de la propriété des biens qu'elle a acquis légalement, de les utiliser, d'en disposer et de les léguer. Nul ne peut être privé de sa propriété, si ce n'est pour cause d'utilité publique, dans des cas et conditions prévus par une loi et moyennant en temps utile une juste indemnité pour sa perte. L'usage des biens peut être réglementé par la loi dans la mesure nécessaire à l'intérêt général.

[DE] Jede Person hat das Recht, ihr rechtmäßig erworbenes Eigentum zu besitzen, zu nutzen, darüber zu verfügen und es zu vererben. Niemandem darf sein Eigentum entzogen werden, es sei denn aus Gründen des öffentlichen Interesses in den Fällen und unter den Bedingungen, die in einem Gesetz vorgesehen sind, sowie gegen eine rechtzeitige angemessene Entschädigung für den Verlust des Eigentums. Die Nutzung des Eigentums kann gesetzlich geregelt werden, soweit dies für das Wohl der Allgemeinheit erforderlich ist.

\footnotetext{
${ }^{53}$ KOSKINEN, Kaisa, "How to research EU translation?", en Perspectives: Studies in Translatology, vol. 9, núm. 4, Manchester y Kinderhook (Nueva York), St. Jerome Publishing, 2001: 294.

Futhark 7 (2012)

Castellano, Análisis del concepto, 43-84

ISSN 1886-9300
} 
[EN] Everyone has the right to own, use, dispose of and bequeath his or her lawfully acquired possessions. No one may be deprived of his or her possessions, except in the public interest and in the cases and under the conditions provided for by law, subject to fair compensation being paid in good time for their loss. The use of property may be regulated by law in so far as is necessary for the general interest.

[IT] Ogni persona ha il diritto di godere della proprietà dei beni che ha acquisito legalmente, di usarli, di disporne e di lasciarli in eredità. Nessuna persona può essere privata della proprietà se non per causa di pubblico interesse, nei casi e nei modi previsti dalla legge e contro il pagamento in tempo utile di una giusta indennità per la perdita della stessa. L'uso dei beni può essere regolato dalla legge nei limiti imposti dall'interesse general.

[PT] Todas as pessoas têm o direito de fruir da propriedade dos seus bens legalmente adquiridos, de os utilizar, de dispor deles e de os transmitir em vida ou por morte. Ninguém pode ser privado da sua propriedade, excepto por razões de utilidade pública, nos casos e condições previstos por lei e mediante justa indemnização pela respectiva perda, em tempo útil. $A$ utilização dos bens pode ser regulamentada por lei na medida do necessário ao interesse geral.

[RO] Orice persoană are dreptul de a deţine în proprietate, de a folosi, de a dispune şi de a lăsa moştenire bunurile pe care le-a dobândit în mod legal. Nimeni nu poate fi lipsit de bunurile sale decât pentru o cauză de utilitate publică, în cazurile şi condiţ̧ile prevăzute de lege şi în schimbul unei despăgubiri juste acordate în timp util pentru pierderea pe care a suferit-o. Folosinţa bunurilor poate fi reglementată prin lege în limitele impuse de interesul general.

En los fragmentos anteriores, que se corresponden con el artículo 17 (de la propiedad) de la Carta de los Derechos Fundamentales de la Unión Europea en siete versiones diferentes las habituales: español, francés, alemán e inglés; más italiano, portugués y rumano- se puede realizar un breve ejercicio para analizar la intertextualidad anterior y aproximarnos a un supuesto TO. Para empezar, debe llamar la atención la posición oracional que tiene la subordinara, aquí resaltada en negrita: «Toda persona tiene derecho a disfrutar de la propiedad de los bienes que haya adquirido legalmente, a usarlos, a disponer de ellos y a legarlos». La cual se 
repite en las versiones francesa, alemana, italiana y portuguesa; mientras que en el caso de la versión inglesa, dicha función queda asumida del siguiente modo: «Everyone has the right to own, use, dispose of and bequeath his or her lawfully acquired possessions", estructura que se repite en la versión rumana: «Orice persoană are dreptul de a deţine în proprietate, de a folosi, de a dispune şi de a lăsa moştenire bunurile pe care le-a dobândit în mod legal’».

Como se aprecia, existen por tanto, en el marco del ejemplo que aquí se estudia, dos posibles TO, uno en el que dicha función aparece en posición inicial y la otra al final de la oración. Además, cabe añadir que la selección de las lenguas no ha sido aleatoria, sino que -dentro de la extensión textual que un trabajo de este tipo permite- han sido seleccionados además de la combinatoria habitual, las otras tres lenguas oficiales que pertenecen a la familia de las lenguas romances (italiano, portugués y rumano); todas ellas con una sintaxis muy aproximada que incluso permite comprender grosso modo el contenido del artículo se sea conocedor o no de la lengua. Por tanto, resultaría lógico esperar que todas las lenguas romances presentasen una estructura similar al español y francés, hecho que se cumple con la versión italiana y portuguesa; pero no con el caso rumano, que además ofrece una estructura similar a la versión inglesa. En este sentido, si somos conscientes de que las lenguas de trabajo interno de los principales organismos de la UE son el alemán, el francés y el inglés y los fragmentos anteriores en esas lenguas muestran a su vez dos posibilidades de TO, ya que el alemán y el francés coinciden en estructura, es posible que tanto la versión inglesa como la francesa fueran TO. O bien, que la versión inglesa tomara una variante en la traducción que fuera reproducida por la versión rumana, ya que ésta tomó del inglés su lengua de partida; pues resultaría muy poco probable que las unidades de traducción al inglés tomaran la versión rumana como texto de partida. 


\section{Hipótesis 1}

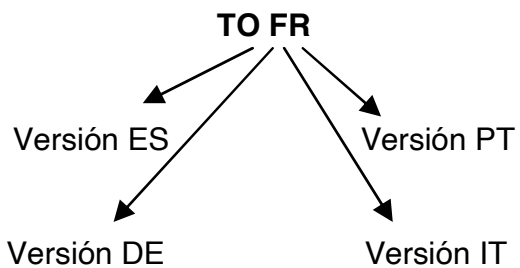

TO EN

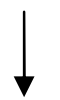

Versión RO

Hipótesis 2

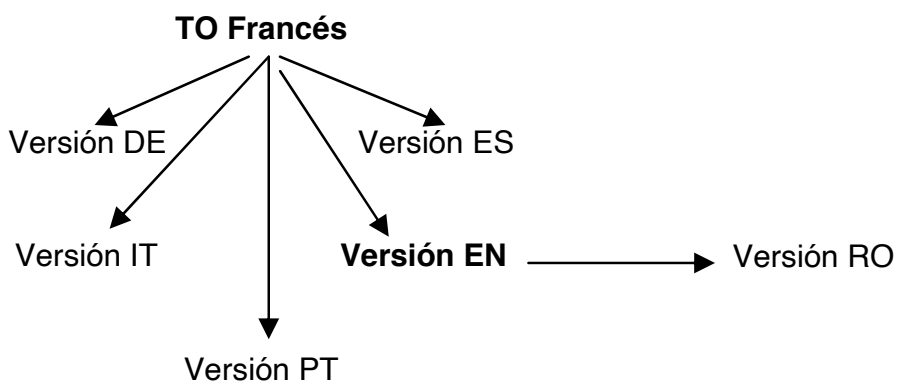

Según lo expuesto, surge el siguiente interrogante: ¿la traducción que se desarrolla en el ámbito institucional de la Unión Europea es, por consiguiente, un proceso o un producto? La respuesta, como no podría ser de otro modo, dependerá del prisma con el que miremos el concepto de traducción. En cuanto al marco jurídico-institucional en el que se inscribe la noción traducción que estudiamos, ésta jamás sería producto, de hecho no se contempla, por lo que se puede deducir que dado a que se exige la existencia de versiones lingüísticas equivalentes en todos los idiomas -y no se conoce otro medio para conseguirlo que no sea la traducción- no queda más remedio que aceptar la traducción, si no como producto, bien como proceso para alcanzar la versión equivalente. Sin embargo, desde el enfoque de este apartado, el traductológico -y en Futhark 7 (2012)

Castellano, Análisis del concepto, 43-84

ISSN 1886-9300 
definitiva el que más interesa- la traducción existe como proceso y como producto, sólo que se trata de una labor profesional de carácter interno y anónimo, aunque no por ello desprestigiado a nivel institucional. Otra visión respecto al concepto de traducción en este marco especializado sería el propuesto por E. Magiera ${ }^{54}$ quien se refiere a la traducción de este tipo de textos más bien como un «diálogo cultural» que se expone a todo tipo de interferencias por parte de las lenguas participantes, ya sean a nivel lingüístico o extralingüístico; aunque de todos modos, para que este diálogo se produzca es necesario el acto traductor.

\section{Propuesta de definición de equivalencia institucional aplicable al ámbito de la Unión Europea}

El concepto de equivalencia en el ámbito de las instituciones de la Unión Europea plantea, de acuerdo con estas tres perspectivas, una reflexión crítica que a la vez resulta idónea para elaborar una propuesta de definición que se aproxime a la noción que este «valor» equivalente supone y al mismo tiempo precisa cualquiera de los documentos generados por las instituciones comunitarias, cuyo contenido sea vinculante para todos los Estados miembros o posea interés comunitario.

Esta realidad, en la que todas las versiones lingüísticas de un instrumento determinado gozan de la misma «equivalencia» -la cual a su vez se ha estudiado desde un punto de vista lingüístico, jurídico y traductológico- es el resultado de un acuerdo previo sobre dicho valor; esto es, se trata de una equivalencia -tanto lingüística como jurídica- previamente acordada. De hecho, M. Guidère ${ }^{55}$ considera que el verdadero problema a la hora de definir el concepto de equivalencia reside en saber de qué tipo de negociación se trata así como a qué nivel del texto hace falta establecer las relaciones de equivalencia. Así, la traducción, entendida como producto final, pierde toda clase de relevancia, puesto que mucho antes incluso de

\footnotetext{
${ }^{54}$ Magiera, Ewa, "La traduction comme dialogue et son rôle particulier au sein des institutions européennes", en KNECHCIAK, Olivier (dir.), Langues européennes en dialogue, Collection Euryopa vol. 62, 2009, págs. 9-21. Recurso disponible en $<$ http://www.unige.ch/ieug/publications/euryopa/Knechciak.pdf> (Fecha de consulta: 25 de enero de 2011).

${ }^{55}$ GUIDERE, Mathieu, Introduction à la traductologie. Penser la traduction : hier, aujourd'hui, demain, Bruselas, De Boeck, 2008, pág. 81.
}

Futhark 7 (2012)

Castellano, Análisis del concepto, 43-84

ISSN 1886-9300 
que se conciban los instrumentos que se van a trasladar a otras lenguas, queda asumida por todas las partes que las diferentes versiones lingüísticas serán iguales en forma y contenido.

Sin embargo, el concepto de acuerdo previo no resulta ser un artificio original de la Unión Europea, es más, en el ámbito del Derecho Internacional se asemejaría a lo que se conoce por "autenticación», es decir, hacer que un instrumento concreto pase a ser legal u oficial, en este caso, en sus diferentes versiones lingüísticas. Por ello, resulta pertinente hacer referencia a la Convención de Viena de 1969 sobre el derecho de los tratados, cuyo artículo 33 reza como sigue:

Artículo 33. Interpretación de tratados autenticados en dos o más idiomas.

1. Cuando un tratado haya sido autenticado en dos o más idiomas, el texto hará igualmente fe en cada idioma, a menos que el tratado disponga o las partes convengan que en caso de discrepancia prevalecerá uno de los textos.

2. Una versión del tratado en idioma distinto de aquel en que haya sido autenticado el texto será considerada como texto auténtico únicamente si el tratado así lo dispone o las partes así lo convienen.

3. Se presumirá que los términos del tratado tienen en cada texto auténtico igual sentido.

4. Salvo en el caso en que prevalezca un texto determinado conforme a lo previsto en el párrafo 1 , cuando la comparación de los textos autenticas revele una diferencia de sentido que no pueda resolverse con la aplicación de los artículos 31 y 39 , se adoptará el sentido que mejor concilie esos textos, habida cuenta del objeto y fin del tratado.

No obstante, lo anterior no significa que todas las traducciones que se realicen de un tratado, y por ende de cualquier instrumento jurídico similar, sean autenticadas ipso facto; de hecho; en ocasiones un mismo instrumento advierte qué versiones serán autenticadas y cuales serán traducciones, que podrán utilizarse como referencia; pero en lo que respecte a los asuntos jurisprudenciales de dicho tratado, únicamente se considerarán auténticas las versiones y no las traducciones, pese a que estas últimas puedan ser oficiales. En este sentido, cabe destacar los 
Convenios de Ginebra de 1949 relativos a la ayuda humanitaria y al derecho de prisioneros en caso de guerra:

\section{Artículo 133 - Idiomas}

El presente Convenio está redactado en francés y en inglés. Ambos textos son igualmente auténticos.

El Consejo Federal Suizo se encargará de que se hagan traducciones oficiales del Convenio en los idiomas ruso y español.

Se trata, pues, de un principio equivalente consensuado, pero que en el caso de la Unión Europea adquiere un aspecto mucho más estricto y simbólico, ya que la UE, como organización supranacional, a diferencia de otras instituciones internacionales, implica tanto a la ciudadanía como a los gobiernos, y conforme a su política lingüística "autentica»-aunque no se denomine como tal a este fenómeno- todo acto o instrumento jurídico que lo precise por propia naturaleza.

Otro aspecto que debe considerarse para aportar una posible definición al concepto de equivalencia en este contexto resulta ser la ficción jurídica que se genera ante esa situación. El pacto previo conlleva a una realidad, que no puede definirse distorsionada sino, más bien ficticia, en la que todas las versiones tienen el mismo valor jurídico. Esta ficción también se manifiesta en el ámbito lingüístico, pues de no ser así, la equivalencia carecería de sentido ya que ¿respecto a qué se tendría que ser equivalente? Resulta evidente que esta situación de equivalencia negociada es condicionante para otros aspectos, que pueden ser al mismo tiempo características inherentes al concepto de equivalencia en este ámbito de especialización.

En principio, se aporta a todas las versiones lingüísticas un sentido de univocidad, autenticidad y originalidad que resulta incompatible con la propia naturaleza de las actividades de traducción. Asimismo, no existe la traducción como producto, más bien como proceso, ya que a nivel interno ésta resulta imprescindible para alcanzar tal realidad de ficción jurídica y lingüística. Por consiguiente, esta noción de equivalencia se caracterizará también por ser aplicable a todas y cada una de las lenguas oficiales de la Unión Europea, indistintamente sea cual sea la familia lingüística a la que pertenezca o las particularidades que la definan; ya que resulta posible traducir en cualquier combinatoria de lenguas, sin que Futhark 7 (2012)

Castellano, Análisis del concepto, 43-84

ISSN 1886-9300 
suponga problema alguno el formulismo, la terminología o incluso la extensión de los fragmentos implicados.

En definitiva, por equivalencia institucional -en el ámbito de la Unión Europea- se puede entender aquel valor igual, polivalente y transversal, previamente acordado en el contexto de aplicación de la Unión Europea, que requiere de un triplete competencial (lingüístico, jurídico y traductológico) para su formulación; que es inherente a todas las versiones lingüísticas de un mismo instrumento o acto sin distinción de lengua, temática o naturaleza del texto en cuestión, ya sea escrito u oral; y que queda legitimado por el Reglamento 1/1958 del Consejo de la UE y las respectivas modificaciones del mismo.

\section{Conclusiones}

Del análisis aquí ofrecido se desprenden una serie de conclusiones que resultan de gran interés para los estudios de traducción, interpretación y terminología en lo que respecta al contexto especializado que las instituciones de la Unión Europea propician por su propia naturaleza.

En primer lugar, de acuerdo con lo visto, se puede afirmar que el concepto de equivalencia no es unívoco, más bien se trata de una idea compartida por una determinada comunidad que al mismo tiempo se presta a múltiples interpretaciones y definiciones dependiendo del ámbito en el que se aplique. Este es el motivo por el que a lo largo de la historia se han desarrollado varias teorías sobre el concepto de equivalencia, donde el único atisbo de relación entre todas ellas ha resultado ser la traducción.

Debido a esta razón, ya que la equivalencia viene condicionada -al igual que el acto de translación lingüística en sí- por una serie de factores determinados como pueden ser la finalidad de la traducción, las características del texto original, las consecuencias que implicaría su contenido en el público receptor o las condiciones de trabajo en las que se desarrollaría la actividad, entre otros aspectos, ha sido pertinente abordar el estudio de este concepto en el ámbito especializado de las instituciones comunitarias a partir de tres diferentes perspectivas, a saber, lingüística, jurídica y traductológica; ya que se podría afirmar que estas nociones crean un contexto único en el que el concepto de equivalencia adquiere unas 
características especificas que no se dan en ninguna otra situación de traducción especializada.

Por una parte, la perspectiva lingüística demuestra que la situación de Multilingüismo en la que se pone en marcha todo el aparato institucional de la Unión Europea implica que cualquier documento -o en su caso instrumento- que sea vinculante para todos los Estados miembros por igual debe disponerse en cada una de las lenguas oficiales de la UE, actualmente 23. La equivalencia cobra, pues, un sentido protagonista sobremanera ya que únicamente será posible esta realidad multilingüe por medio de la traducción.

Por otra, la perspectiva jurídica, que viene establecida por el acervo comunitario, resulta responsable indiscutible de la situación lingüística anterior, que contempla el concepto de equivalencia más bien como un valor simbólico e intrínseco a cualquier instrumento vinculante y no como equilibrio entre TO y TM, más propio del ámbito de la traductología. De este modo, al concepto de equivalencia se le otorga un matiz de significado que dista del resto de teorías reseñadas al principio de este trabajo, pues esta equivalencia encierra un valor simbólico y jurídico adicional al lingüístico; aunque no se trata de un valor jurídico como el que pudiera tener una traducción jurada, dicho de otro modo, se trata de un valor jurídico pertinente exclusivamente a la Unión Europea y al marco jurídico e institucional en el que se inscribe.

Finalmente, la perspectiva traductológica -quizá la más interesante aunque a efectos oficiales la menos condicionanterevela una serie de consideraciones en lo que respecta al acto de translación lingüística así como a las nociones de TO y TM en este ámbito. En principio, al igual que ocurre con el concepto de equivalencia, la labor traductora viene condicionada de igual modo por los factores anteriores así como por la propia metodología de trabajo de los servicios lingüísticos de los diferentes órganos de la Unión Europea. No existe un modus operandi homogéneo para estos traductores, tampoco siquiera para cada una de las unidades en las que operan. Cierto es que gozan de una determinada autonomía dentro de la cual pueden hacer uso tanto de memorias de traducción, como de bases de datos, herramientas de dictado o programas de modificación de documentos anteriores como DocuCom. En cuanto al TO y TM, queda manifiesta la inexistencia de estos conceptos como tales, ya que las perspectivas anteriores demuestran que todas las lenguas, al tener el mismo rango oficial, Futhark 7 (2012) Castellano, Análisis del concepto, 43-84 ISSN 1886-9300 
no pueden ser ni punto de partida ni punto de llegada en lo que se refiere a una traducción; prefiriéndose el uso de «versión lingüística», mientras que la traducción se mantiene como un proceso invisible, paralelo a la misma elaboración textual aunque, al mismo tiempo, indispensable.

Asimismo, con este análisis también se ha destacado la existencia de determinados aspectos que, a partir de un enfoque transversal, surgen al tratar la cuestión equivalente. Claro ejemplo de ello es la realidad de ficción jurídica en la que se generan los instrumentos comunitarios así como todas sus versiones lingüísticas. Un panorama de valor equivalente que ha sido previamente «negociado» en este ámbito institucional, por lo que se asume a priori la equivalencia de cualquiera de dichas versiones.

En definitiva, este trabajo propone un enfoque particular en lo que concierne al concepto de equivalencia en el ámbito institucional de la Unión Europea, por lo que a tenor de todas las consideraciones anteriores se ofrece una posible definición de concepto de acuerdo con el contexto de especialización. Esta propuesta no sólo se ciñe a los aspectos puramente lingüísticos, sino que resulta aplicable de igual modo a los valores simbólicos y jurídicos que el marco institucional de la UE conlleva.

\section{REFERENCIAS BIBLIOGRÁFICAS}

BASSNET, Susan, Translation Studies, Londres y Nueva York, Routledge, 1980.

Bolaños CuelLaR, Sergio, "Equivalence Revisited: a Key Concept in Modern Translation Theory", en Forma y Función (Revista de la Facultad de Ciencias Humanas-Departamento de Lingüística de la Universidad Nacional de Colombia), núm. 15, 2002, págs. $60-80$.

BRACKENIERS, Eduard, "Europe without frontiers and the language challenge", en Terminologie \& Traduction. núm. 2, Luxemburgo, Oficina de Publicaciones oficiales de las Comunidades Europeas, 1995, págs. 13-17.

BUCHIN, Nicole; HaLLER, Gudrun, "Implications politiques des choix terminologiques", en Terminologie \& Traduction, núm. 1, 
Luxemburgo, Oficina de Publicaciones oficiales de las Comunidades Europeas, 1999, págs. 14-20.

CATFORD, John C., A Linguistic Theory of Translation: an Essay on Applied Linguistics, Londres, Oxford University Press (OUP), 1965.

Convención de Viena sobre el Derecho de los Tratados de 1969.

Recurso disponible en

$<$ http://www.oas.org/XXXVGA/espanol/doc referencia/Conve ncion_Viena.pdf> (Fecha de consulta: 2 de febrero de 2011)

Convenios de Ginebra de 1949. Recurso disponible en $<$ http://www.icrc.org/web/spa/sitespa0.nsf/html/genevaconve ntions\#a1> (Fecha de consulta: 2 de febrero de 2011).

Cosmal, Domenico, "L'idioletto politico delle istituzioni europee: caratteristiche e approcci traduttivi", en Terminologie \& Traduction, núm. 2, Luxemburgo, Oficina de Publicaciones oficiales de las Comunidades Europeas, 2000, págs. 5-28.

FORREST, Alan, "The challenge of languages in Europe", en Terminologie \& Traduction, núm. 3, Luxemburgo: Oficina de Publicaciones oficiales de las Comunidades Europeas, 1998, págs. 101-120.

GAMBIER, Yves, "Mouvances eurolinguistiques. Cas de la Finlande", en BALLARD, Michel (ed.), Europe et traduction. Arras: Artois Presses Université. pp. 295-304, 1998.

GIDOVA, Klaudia, "EU Translation as the Language of a Reunited Europe Reconsidered", en FERENČík, Milan; HORVÁTH, Juraj (eds.), Language, Literature and Culture in a Changing Transatlantic World, 2009, págs. 145-153. Recurso disponible en < http://www.pulib.sk/elpub2/FF/Ferencik2/> (Fecha de consulta: 30 de enero de 2011).

GoFFIN, Roger, "L'Europe en neuf langues: champ d'affrontements et ferment d'intégration linguistiques", en Meta: journal des traducteurs / Meta: Translators' Journal, vol. 35, núm. 1, 1990, págs. 13-19.

GUIDERE, Mathieu, Introduction à la traductologie. Penser la traduction : hier, aujourd'hui, demain, Bruselas, De Boeck, 2008 
Hatim, Basil; MASON, lan, Teoría de la traducción. Una aproximación al discurso, Barcelona, Ariel, 1995.

HEYNOLD, Christian, "L'Union européenne: Jardin d'Éden ou Tour de Babel ?", en Terminologie \& Traduction, núm. 3, Luxemburgo, Oficina de Publicaciones oficiales de las Comunidades Europeas, 1999, págs. 5-14.

HIGASHINO, Yumi, "Cultural equivalence: its effectiveness and complications. Has «white gloves" achieved the equivalent effect of «shiro tabi»?", en Interpretation Studies (JAIS, the Japan Association for Interpretation Studies), núm. 1, 2001, págs. 53-63.

JACKOBSON, Roman, On linguistic Aspects of Translation, Nueva York, R.A. Broker, 1966.

JANSSEN, Maarten; VAN CAMPENHOUDT, Marc, "Terminologie traductive et représentation des connaissances : I'usage des relations hyponymiques", en Langages, núm. 157, Luxemburgo, Oficina de Publicaciones oficiales de las Comundiades Europeas, 2005, págs. 63-79.

Jerga de la Unión Europea. Recurso disponible en $<$ http://europa.eu/abc/eurojargon/index_es.htm> (Fecha de consulta: 29 de enero de 2011).

KJAER, Anne. L, "Legal Translation in the European Union. A Research Field in Need of a New Approach", en KREDENS, K.; GoźDż-RoszKowSKı S. (eds.), Language and the Law: International Outlooks, Fráncfort del Meno, Peter Lang, 2007, págs. 69-95.

KOLLER, Werner, "Der Begriff der Äquivalenz in der Übersetzungswissenschaft", en FABRICIUS-HANSEN, C.; OstBo, J. (eds.), Übertragung Annährung, Angleichung. Sieben Beiträge zu Theorie und Praxis des Übersetzens, Fráncfort del Meno, Peter Lang, 2000.

KOLLER, Werner, Einführung in die Übersetzungswissenschaft, Heidelberg, Quelle \& Meyer, 1979.

KOSKINEN, Kaisa, "How to research EU translation?", en Perspectives: Studies in Translatology, vol. 9, núm. 4, 
Manchester y Kinderhook (Nueva York), St. Jerome Publishing, 2001, págs. 293-325.

KOSKINEN, Kaisa, "Institutional Illusions. Translating in the EU Commision", en The Translator, vol. 6, núm. 1, Manchester y Kinderhook (Nueva York), St. Jerome Publishing, 2000, págs. 49-65.

KoskINEN, Kaisa, "From Text to Context", en HELIN, Irmeli (ed.), Essays in Translation, Pragmatics and Semiotics, Helsinki: Multilingual Communication programme (MonAKO), 2002, págs. 111-128.

MAGIERA, Ewa, "La traduction comme dialogue et son rôle particulier au sein des institutions européennes", en KNECHCIAK, Olivier (dir.), Langues européennes en dialogue, Collection Euryopa vol. 62, 2009, págs. 9-21. Recurso disponible en $<$ http://www.unige.ch/ieug/publications/euryopa/Knechciak.p df $>$ (Fecha de consulta: 25 de enero de 2011).

MORATINOS JOHNSTON, Sofía, "Multilingualism and EU Enlargement", en Terminologie \& Traduction, núm.3, Luxemburgo: Oficina de Publicaciones oficiales de las COmunidades Europeas, 2000, págs. 5-70.

MUÑOZ MARTín, Francisco Javier; Valdivieso BLANCO, María, "Traductores y especialistas en la Unión Europea. Hacia el binomio integrador", en Tonos digital: Revista electrónica de estudios filológicos, núm. 12, 2006. Recurso disponible en $<$ http://www.um.es/tonosdigital/znum12/subs/indice/IndiceTo nos.htm> (Fecha de consulta: 31 de enero de 2011).

MúRIAS, Augusto, "A propósito do multilinguismo sob especial consideração da língua portuguesa", en Terminologie \& Traduction, núm. 1, Luxemburgo: Oficina de Publicaciones oficiales de las Comunidades Europeas, 1999, págs. 59-91.

Newmark, Peter, A Textbook of Translation, Hertfordshire, Prentice Hall International, 1988.

NIDA, Eugene, Toward a Science of Translating with Special Reference to Principles and Procedures involved in Bible Translation, Leiden y Boston, Brill, 1964. 
PEÑA, Salvador; HERNÁNDEZ GUERRERO, María Jose,

Traductología, Málaga: Universidad de Málaga, 1994.

PEYRó, Francisco, "Le "qui-dit-quoi" de l'acquis communautaire", en Terminologie \& Traduction, núm. 2, Luxemburgo, Oficina de Publicaciones oficiales de las Comunidades Europeas, 1999, págs. 52-75.

PoPovič, Anton, Dictionary for the Analysis of Literary Translation, Edmonton, Department of Comparative Literature - University of Alberta, 1976.

Reglamento (UE) n ${ }^{\circ} 540 / 2010$ del Parlamento Europeo y del Consejo, de 16 de junio de 2010 , que modifica el Reglamento (CE) $n{ }^{\circ} 1085 / 2006$ del Consejo, por el que se establece un Instrumento de Ayuda Preadhesión (IPA).

Recurso disponible en $<$ http://eurlex.europa.eu/Notice.do?val $=518140:$ cs\&lang=es\&list $=55403$ 0:cs,553956:cs,550559:cs,523256:cs,520274:cs,518140:cs,5 13312:cs,511119:cs,504255:cs,502354:cs, \&pos=6\&page $=1 \&$ nbl=53\&pgs $=10 \&$ hwords $=$ acquis $\% 20$ communautaire $\sim$ check texte=checkbox\&visu=\#texte $>($ Fecha de consulta: $29 \mathrm{de}$ enero de 2011)

Reglamento 1/1958 del Consejo. Recurso disponible <http://eurlex.europa.eu/LexUriServ/LexUriServ.do?uri=CELEX:31958 R0001:es:NOT> (Fecha de consulta: 28 de enero de 2011)

Repercusiones del Tratado de Lisboa en la evolución del equilibrio institucional en la Unión Europea Resolución del Parlamento Europeo, de 7 de mayo de 2009 , sobre las repercusiones del Tratado de Lisboa en la evolución del equilibrio institucional en la Unión Europea (2008/2073(INI)). Recurso disponible en <http://eurlex.europa.eu/Notice.do?val=520890:cs\&lang=es\&list $=55556$ 2:cs, 554801:cs, 554773:cs, 554423:cs, 553968:cs,523493:cs, 5 23499:cs,523173:cs,520890:cs,520062:cs, \&pos=9\&page=1\& $\mathrm{nbl}=117 \& \mathrm{pgs}=10 \&$ hwords=eurogrupo $\&$ checktexte=checkbo

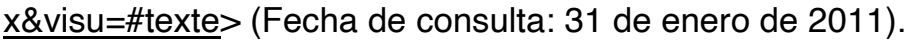

SÁNCHEZ TRIGo, Elena, Teoría de la traducción. Convergencias y divergencias, Vigo, Servicio de Publicaciones de la Universidad de Vigo, 2002. 
ŠARCEVIC, Susan, "Preserving Multilingualism in an Enlarged European Union", en Terminologie \& Traduction, núm. 2, Luxemburgo, Oficina de Publicaciones oficiales de las Comunidades Europeas, 2001, págs. 34-50.

ŠARCEVIC, Susan, New Approach to Legal Translation, La Haya, Kluwer Law International, 1997.

Tratado constitutivo de la Comunidad Europea de la Energía Atómica (CEEA - EURATOM), 1957. Recurso disponible en $<$ http://eur-lex.europa.eu/es/treaties/index.htm> (Fecha de consulta: 28 de enero de 2011).

VAN ELS, Theo. J. M, "The European Union, its Institutions and its Languages: Some Language Political Observations", en Current Issues in Language Planning, vol. 2, núm. 4, Londres, pp. 311-360, 2001.

WAGNER, Emma; BECH, Svend; MARTíNEZ, Jesús M, Translating for the European Union Institutions, Manchester, St. Jerome Publishing, 2002. 